\title{
Sudden Death in Infancy: A Microbiological and Epidemiological Study
}

\author{
R. N. P. SUTTON* and J. L. EMERY \\ From the University of Sheffield Virus Research Laboratory and the Department of Pathology, \\ Children's Hospital, Sheffield
}

With the decreasing general infant mortality in Western countries, unexpected death is bidding fair to become a leading cause of mortality in the second, third, and fourth months after birth. It has been estimated (Ministry of Health, 1965) that about 1090 such deaths occur each year in England and Wales, a frequency of 1.4 per 1000 live births.

Increasing attention has been paid to this problem during the past two decades and many notions as to its aetiology have been put forward (Valdés-Dapena, 1963). Three hypotheses are now popular. They are (i) suffocation, probably from soft bedding; (ii) hypersensitivity to milk proteins; (iii) overwhelming infection, probably viral. The first two of these have received a fair amount of study (Parish, Barrett, Coombs, Gunther, and Camps, 1960; Lancet, 1965; Emery, 1959a), but in the investigation of possible viral infections rather less has been attempted and the value of much of this has been superseded by recent developments in the cultivation of viruses (Stuart-Harris, 1962). The time seemed ripe, therefore, to carry out an epidemiological and microbiological study over a limited period in Sheffield.

\footnotetext{
Methods

We defined 'sudden death' as the death of a child who was thought to be in good health or whose terminal illness appeared to be so mild that the possibilities of a fatal outcome were not anticipated (Adelson and Kinney, 1956). Immediately upon notification of such a death to the Pathology Department of the Children's Hospital (normally via the Coroner), one of us (R.N.P.S.) visited the family and inquired about any history of illness during the previous few days. A physical examination was made where indicated. Nose and throat swabs were then taken from all available contacts of the dead child and were examined for viruses (pooled nose and

Received March 15, 1966.

$\star$ Present address : Department of Microbiology, Institute of Child Health, and The Hospital for Sick Children, Great Ormond Street, London W.C.1.
}

throat swabs) and bacteria (throat swabs only), using the methods adopted by the Medical Research Council Working Party on Acute Respiratory Virus Infection (1965). As 24 to 48 hours had usually elapsed between the time of death and our being informed, no postmortem specimens were examined for viruses. Small pieces of lung and trachea were, however, taken and stored at $-70^{\circ} \mathrm{C}$.; these have not yet been examined. General post-mortem examinations of the dead infants were carried out by one of us (J.L.E.). The cases studied occurred between September 12, 1963, and February 3, 1964. During that time 21 unexpected child deaths were dealt with by the Pathology Department and, of these, 10 were investigated from a microbiological viewpoint as described above.

Pari passu with this study, an investigation of respiratory illness in a group of Sheffield families with young children was in progress; this study has been reported, in part, elsewhere (Medical Research Council, 1965). It formed background and control data.

\section{Results}

The investigation was in two parts, a retrospective study of sudden deaths in infancy during the period 1961-1964 and a prospective study of similar deaths during the period 1963-1964.

The retrospective study. During the years 1961-1964 longitudinal studies of the prevalence and aetiology of respiratory and other disease in the Sheffield area were in progress (Sutton, 1965; Medical Research Council, 1965; J. Finbow, D. Hobson, G. C. Schild, and J. S. Oxford, 1961-1964, unpublished work). Over this period, volunteer families scored their experience of respiratory illness on record cards of the Hope Simpson type (Hope Simpson, 1958; Sutton, 1961, 1965). Laboratory methods used for the recovery of viruses varied over the years, with the increasing range of viruses being sought. In Fig. 1, the prevalence of respiratory illness and of unexpected deaths in infancy in Sheffield during the years 1961-1964 is plotted, together with details of virus recoveries during the same period. There are peaks in incidence of 


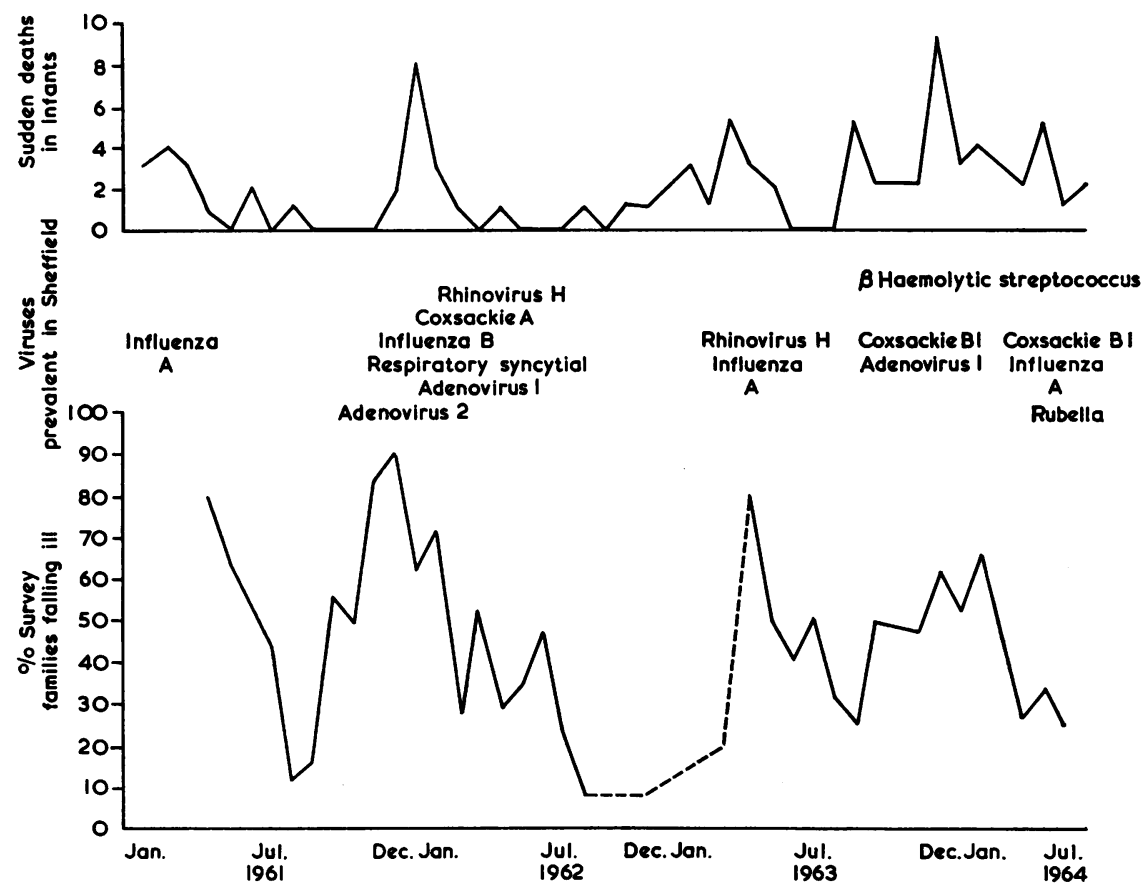

Fig. 1.-Sudden deaths in infancy and respiratory illness in the community: Sheffield 1961-1964. (Broken line = estimated prevalence.)

respiratory illness and of unexpected deaths in (i) January 1961, when Influenza A virus was present in the community, (ii) in January 1962, when Influenza B virus was present, (iii) in March 1963, when Influenza A virus was present, and (iv) also in the winter of 1963-1964, when Coxsackie B1 and Influenza A viruses were present.

The prospective study. In the 10 instances of unexpected death in infancy which were studied, the families were visited and specimens taken as described. These families were large (4-9 individuals, mean size $6 \cdot 1$ ) as opposed to the control families (3-7 individuals, mean size 4.2). All but one of the families in which sudden deaths of infants had occurred were, in some respects, 'problem families' (Blacker, 1952). The dead infants had been from 2-16 weeks of age at the time of death (mean age 9.3 weeks) and all save one had been bottle-fed. Of the 50 contacts of the dead infants, $19(38 \%)$ were 5 years of age or less; in the control group, 57 of 189 infants $(30.2 \%)$ were 5 years of age or less, a barely significant difference $(p<0.05)$.

In Fig. 2 is given the incidence of respiratory illness in the contacts during the 10 days preceding and the 10 days following the death. A peak of incidence occurs between the two days preceding and the two days following the death. During this period $30 / 50(60 \%)$ of the infants' contacts experienced respiratory illness ranging in severity from common colds (20 instances) to bronchitis and otitis media (4 instances each) and bronchopneumonia (1 instance). 29 specimens from these contacts were investigated for viral and

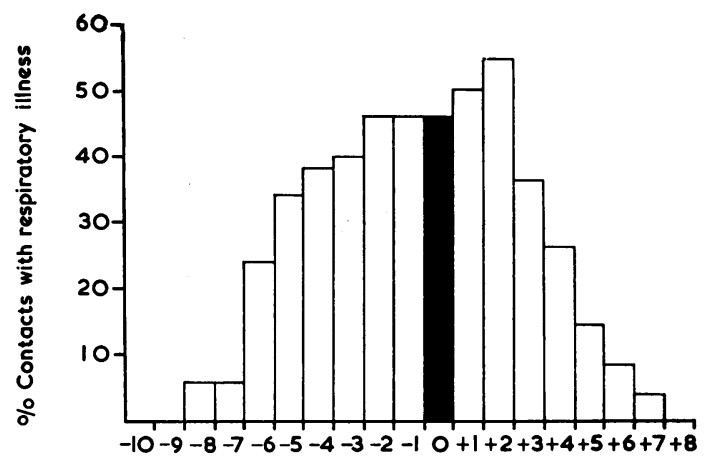

FIG. 2.-Respiratory illness in the family contacts of infants dying suddenly. Days before (-) or following ( + sudden death of infant (O). 
bacteriological pathogens. One unidentified enterovirus was recovered from a 14-year-old girl with otitis media. Throat swabs from 13 contacts, 8 of whom were suffering from respiratory illness, yielded 16 strains of pathogenic bacteria. These were $\beta$-haemolytic streptococci (11), Staphylococcus pyogenes (3), Haemophilus parainfluenzae (1), and Streptococcus pneumoniae (1). In these families, therefore, $13 / 29$ contacts $(44 \cdot 8 \%)$ yielded pathogenic bacteria and 11/29 (37.9\%) yielded $\beta$-haemolytic streptococci. In the control families, $20 / 102$ $(19.6 \%)$ individuals in families with respiratory illness present yielded pathogenic bacteria (all of which were $\beta$-haemolytic streptococci). The rate of recovery of pathogenic bacteria and of $\beta$-haemolytic streptococci in the contacts of the dead infants was significantly higher $(p<0.01)$ than the rate in the control families (which may be taken as similar toand certainly no lower than-the carrier rate in the community at the time of the study). The 21 infants who died unexpectedly during this survey ranged in age from 2 days to 5 years; all but 5 were between 2 weeks and 6 months of age. $4(20 \%)$ had mild previous symptoms affecting the intestines, 1 $(5 \%)$ had symptoms affecting the central nervous system, and $13(65 \%)$ had respiratory tract symptoms.
The post-mortem findings were all of a microscopical nature. The most common findings were those of fluid exudate into alveoli $(70 \%)$ and the formation of alveolar membranes (65\%) (Fig. 3). Five showed possible earliest stages of pneumonia, 3 showed purulent bronchiolitis, 3 showed interstitial emphysema of the lung, and one showed antemortem pulmonary venous thrombosis. These latter were usually in combination with the two most common lesions.

The thymus showed the earliest histological changes associated with 'stress' in 7 cases (30\%) (Emery, 1964) and early fatty changes in the liver in 5. There was a small amount of increased cellularity beneath the basement membrane of the trachea in $11(50 \%)$ of the infants but of such a degree as barely to constitute a diagnosis of an acute tracheitis.

These post-mortem changes differed in no way from the findings in several hundred of similar 'cot' and unexpected deaths studied in Sheffield during the past 10 years.

\section{Discussion}

Recent reports on the relation of virus infections to unexpected deaths in infancy have yielded conflicting results. Moore, Hooser, Davis, and

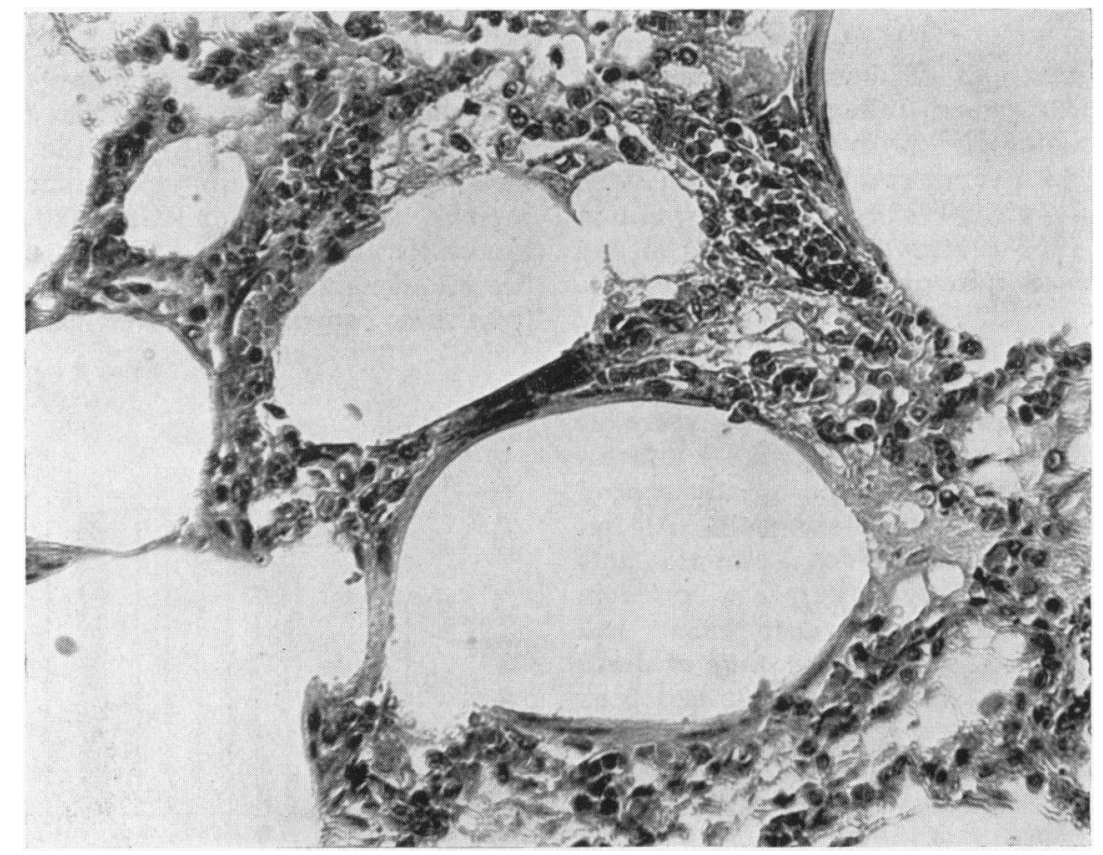

FIG. 3.-The most characteristic lung findings in this series of deaths are shown. Peripheral alveoli are partially collapsed and contain fluid of a high protein content, and there are central enlarged cyst-like acini, with flatiened cells in their walls, forming an intra-alveolar membrane. (Haematoxylin and eosin. $\times 400$.) 
Siem (1964) recovered a virus prevalent in the locality (ECHO 7) from faeces and other organs of 7 of 10 infants at necropsy, and Gold, Carver, Heineberg, Adelson, and Robbins (1961) recovered enteroviruses (Coxsackie A4, A8, poliovirus 3, and unidentified viruses) from 12 of 50 instances of sudden death. Valdés-Dapena and Hummeler (1963) recovered only 2 viruses from 109 infants at necropsy and, in a survey of the published papers, found a net recovery rate of only $0.4 \%$ in 254 necropsies of infants dying suddenly. It is perhaps quite unjustifiable to compare these findings, as the number and types of viruses recovered depend upon a large number of secondary factors, including the orientation of the investigating laboratory. Perhaps of equal importance is the tissue available for study-thus, postmortem tissue taken a number of hours after death (as done by Valdés-Dapena and Hummeler, 1963) is much less likely to yield positive results on culture than material taken from living contacts. The importance of respiratory illness, either in the infant or in the family, is borne out by our study and by that of Coe and Hartmann (1960), who observed that in $40 / 76(52.7 \%)$ instances of sudden death, either the infant or the family had experienced some sort of respiratory infection, and by the environmental histories of many of the cases (Emery, 1959b).

As in other studies, we found the squalor of the families concerned to be outstanding and this may be reflected in the high rate of recovery of pathogenic bacteria. It is possible that bacterial infection alone precipitated the fatal chain of events in the children we investigated; it may well be that bacterial and viral infection combined synergistically, as has been postulated in infantile gastro-enteritis (Cramblett and Siewers, 1965). In this context, it is well to remember that methods for the recovery of viruses are not yet infallible and, though our methods would have detected most of the respiratory and enteroviruses known in 1964, they would not have detected some of the more recently described respiratory viruses (Tyrrell and Bynoe, 1966). It is in this context that our observations are significant. They show that the incidence of unsuspected death in infants runs parallel to that of minor respiratory illness in the local community and is especially related to epidemics of influenza. We do not yet know the cause or, more probably, series of causes (Carpenter and Shaddick, 1965) that precipitate these unexpected infant deaths but our findings suggest that environmental infections are in some way directly so related.

\section{Summary}

The incidence of respiratory illness in the community and the unexpected deaths in infancy in the city of Sheffield during the years 1961-1964 showed a close correlation, especially during epidemics of influenza. The contacts of 10 infants who died in this way were investigated for pathogenic viruses and bacteria. The proportion of these contacts who harboured such bacteria was significantly higher than that in a control population.

\section{REFERENCES}

Adelson, L., and Kinney, E. R. (1956). Sudden and unexpected death in infancy and childhood. Pediatrics, 17, 663.

Blacker, C. P. (1952). (ed.) Problem Families: Five Inquiries. Eugenics Society, London.

Carpenter, R. G., and Shaddick, C. W. (1965). Role of infection, suffocation, and bottle-feeding in cot death. An analysis of some factors in the histories of 110 cases and their controls. Brit. F. prev. soc. Med., 19, 1.

Coe, J. I., and Hartmann, E. E. (1960). Sudden unexpected death in infancy. $\mathcal{F}$. Pediat., 56, 786.

Cramblett, H. G., and Siewers, C. M. F. (1965). The etiology of gastroenteritis in infants and children, with emphasis on the occurrence of simultaneous mixed viral-bacterial infections. Pediatrics, 35, 885.

Eniery, J. L. (1959a). Epidemiology of 'sudden, unexpected, or rapid' deaths in children. Brit. med. F., 2, 925.

- (1959b). 'Sudden and unexpected' death in infancy. Proc. roy. Soc. Med., 52, 890.

(1964). The assessment of the duration of illness in children unexpectedly dead. Med. Sci. Law, 4, 39.

Gold, E., Carver, D. H., Heineberg, L., Adelson, L., and Robbins, F. C. (1961). Viral infection: A possible cause of sudden, unexpected death in infants. New Engl. F. Med., 264, 53.

Hope Simpson, R. E. (1958). Symposium on the epidemiology of non-infectious diseases (a) Common upper respiratory diseases. Roy. Soc. Hlth F., 78, 593.

Lancet (1965). Cot deaths. 2, 889.

Medical Research Council Working Party on Acute Respiratory Virus Infection (1965). A collaborative study of the aetiology of acute respiratory infections in Britain 1961-4. Brit. med. $\mathcal{F}$., $2,319$.

Ministry of Health (1965). Enquiry into sudden death in infancy. Reports on Public Health and Medical Subjects, No. 113.

Moore, M. L., Hooser, L. E., Davis, E. V., and Siem, R. A. (1964). Sudden unexpected death in infancy: Isolations of ECHO type 7 virus. Proc. Soc. exp. Biol. (N.Y.), 116, 231.

Parish, W. E., Barrett, A. M., Coombs, R. R. A., Gunther, M., and Camps, F. E. (1960). Hypersensitivity to milk and sudden death in infancy. Lancet, 2, 1106.

Stuart-Harris, C. H. (1962). Viruses of diseases of the respiratory tract. Brit. med. $\mathcal{F} ., 2,869$.

Sutton, R. N. P. (1961). A family study of respiratory illness. 7. Coll. gen. Practit., 4, 597. (1965). Minor illness in Trinidad: a longitudinal study. Trans. roy. Soc. trop. Med. Hyg., 59, 212.

Tyrrell, D. A. J., and Bynoe, M. L. (1966). Cultivation of viruses from a high proportion of patients with colds. Lancet, 1, 76.

Valdés-Dapena, M. A. (1963). Sudden and unexpected death in infants. The scope of our ignorance. Pediat. Clin. N. Amer., 10, 693.

, and Hummeler, K. (1963). Sudden and unexpected death in infants. II. Viral infections as causative factors. $\mathcal{f}$. Pediat., 63, 398. 